Special Issue of the 6th International Congress \& Exhibition (APMAS2016), Maslak, Istanbul, Turkey, June 1-3, 2016

\title{
Examination of the Electric Field Intensity Distribution Between Wet Surfaces During Cable Aging Process
}

\author{
I. Gunes* \\ Istanbul University, Faculty of Engineering, Department of Electrical Engineering and Electronics, \\ Avcilar Campus, Avcilar 34320, Istanbul, Turkey \\ In this study, electric field effect was investigated by dry band arcing test method. ADSS (all-dielectric self- \\ supporting) cables are usually placed on power grids. These cables are affected by temperature and are exposed \\ to many environmental effects such as wind and UV rays. In this study, the effect of water flow over ADSS cable \\ on electric surface erosion on dry surfaces was investigated by electric arcing method, according to IEEE 1222 \\ standard and the electric field intensity at the surface and the electric potential distribution were analyzed using \\ the finite element method.
}

DOI: 10.12693/APhysPolA.131.548

PACS/topics: Cable insulation, electric field, dry band arcing, aging test

\section{Introduction}

ADSS (all-dielectric self-supporting) cables are used in transmission lines and are installed 3-6 $\mathrm{m}$ below the high voltage conductors [1]. Throughout their service life ADSS cables, stretched between poles of a high voltage transmission line, suffer from several degradation mechanisms, such as humidity, pollution, ice load, wind, temperature variations, etc., which have a vital effect on the ageing and degradation process of the cables [2]. In addition to the necessary tensile strength, cable manufacturers have also to consider the electric stress mechanisms, which lead to accelerated aging and finally damage or destruction of the cable jacket [3].

Wind causes a mechanical stresses on ADSS cables and hence stretches the outer insulation of the fiber-optic cable.

This mechanical effect together with the corona discharge decreases the lifetime of the cable jacket considerably. In this study the effect of electric field on the aging behavior of ADSS cables is investigated [4].

In electric industry, the cheaper and safer transfer of energy is an important problem. Industry needs higher voltage in order to transport big amounts of energy. The problems which appear at high voltages are discharge events, safety and environmental factors. In industry, solid insulators are employed more often than gas or liquid ones, as solid insulators are substantially better by comparison with gas and liquid ones. A good dielectric material has to have low dielectric loss, high mechanical strength and resistance to moisture, chemical interactions and temperature. It should not also be affected by the environmental conditions [5].

The damage analysis has been performed in order to establish a relation between the electric field and life time

\footnotetext{
*e-mail: gunesi@istanbul.edu.tr
}

of ADSS cable. The cable damage was observed as an erosion of the poly ethylene (PE) sheath of the cable between the clamps. Due to the rapid drying of the liquid, hot spots with a very high temperature are created on the surface of the cable. This process leads to the generation of dry ring zones and partial arcing.

Damage is usually observed in the form of small holes and spongy residues, similar to the classical tree pictures found in many tracking and erosion tests [6]. The main purpose of the present paper was to study the datasets produced according to IEEE 1222 test standard and to find out whether the effect of electric field could be integrated in a simplified set of surface degradation test methods [7].

Solid dielectrics experience different climatic and contamination conditions in their service life, which ruin their dielectric properties. During their service life polymers are exposed to many different environmental stresses like humidity, contaminants, etc. In our previous studies aging and degradation properties of polymeric insulators were investigated in detail [8]. It is desirable to conduct accelerated aging tests on insulators that simulate real life conditions, in which the insulators are expected to perform well for long term. Dry band arcing test method is a well known surface tracking test method. In this method discharges are formed by constant contaminant flow rate on the insulation surface. These discharges caused surface degradation. IEEE 1222 standard is a quite simple and fast test method to evaluate the aging process capability of polymeric materials.

Finite element method (FEM) has been used in many fields such as electric engineering, medicine technology, geology, engineering etc. The method is based on a quasistatic approximation obtained by neglecting the electric field induced by the magnetic field, which is produced by the current. The problem is reduced to finding a solution to Laplace equation, that satisfies the normal boundary conditions, such as in the electrostatic case, and supplementary boundary conditions [9]. 
In this research, a model based on FEM has been proposed to estimate the electric field of solid insulator material, which was aged according to dry band arcing test method (IEEE 1222). A finite-element model for potential and electric-field calculation along cable insulation sample is presented. With commercial FEM software FEMLAB, a finite-element model for potential and electric-field calculation along a cable insulator is presented [10].

\section{Materials and methods}

In FEM the problem is divided into the smaller problems, which are easier to solve. Solving a problem in FEM consist of four different steps: (i) divide the problem into inferior regions; (ii) define the equations in the subdomains and define the initial conditions; (iii) combine the solutions for subdomains; (iv) find the solution of the resulting system of equations. Solving electrostatic field problems with FEM is based on minimizing the energy.

In this study all samples have been drawn according to IEEE 1222 test standard (dry band arcing test) [6]. The electric scheme of the measurement setup, test samples and there dimensions are given in Fig. 1. The electrodes were made of aluminum and were corrosion resistive. Parameters which are presented in Fig. 1 were used in the FEM.
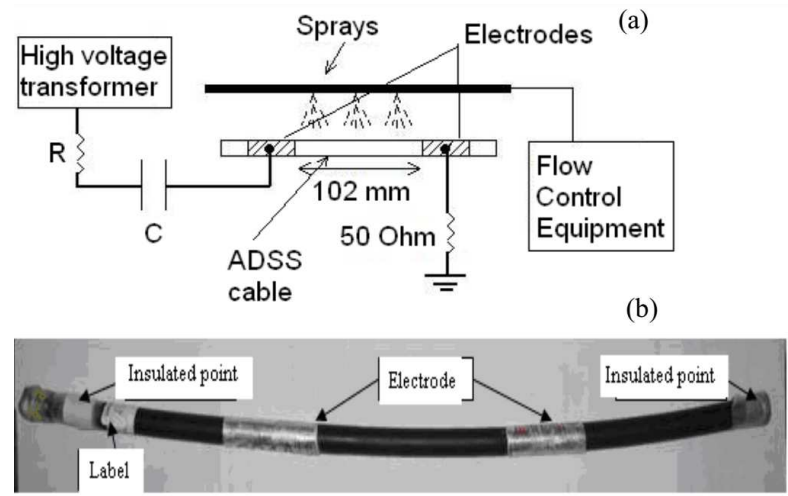

Fig. 1. a) Block diagram of the dry band arcing test setup, b) cable test sample.

\section{Results and discussion}

In this research, solid poly ethylene cable insulator was modeled according to IEEE 1222 test standard by using FEM. First, the insulator, electrodes and the flowing liquid contaminant channels were designed. We draw one channel starting from the high voltage electrode and then divide this channel into three other branches, to make the different contaminant paths somewhere near the ground electrode. This is similar to what happened during the experimental procedure. The electrodes are modeled with the dimensions of $1 \mathrm{~mm}$ which is the case for the contacts of high voltage and ground electrodes with the sample surface. Then, the sub domain, edge and boundary settings are defined for each element used in model, as was described in Section 2. A triangle mesh model was used in this study, as shown in Fig. 2. The areas with higher electric field potential have a high density of meshing. These are places near the high voltage and ground electrode and beneath the liquid.

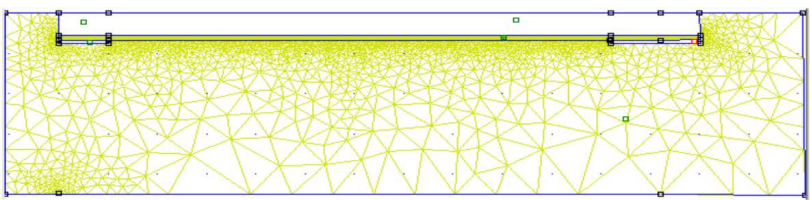

Fig. 2. Finite element mesh of test sample.

In Fig. 3 simulated solid insulator, electric potential and electric field lines are shown for a polymer with a relative permittivity value of insulation of the test cable.

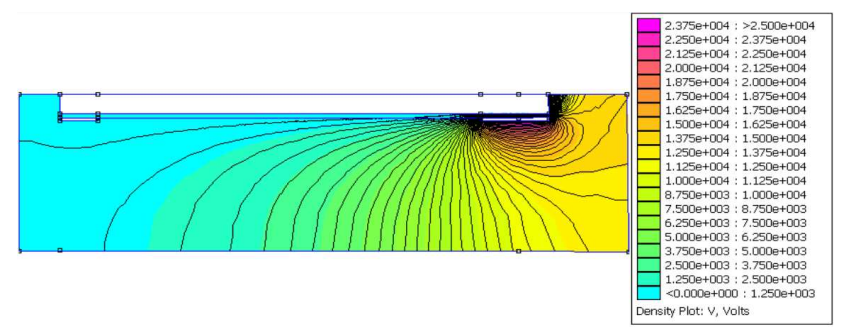

Fig. 3. Plot of electric field distribution for solid poly ethylene cable insulator.

The results are shown in Figure 4. Increasing relative permittivity, results in an increase in the electric potential values through the cable insulator sample surface.

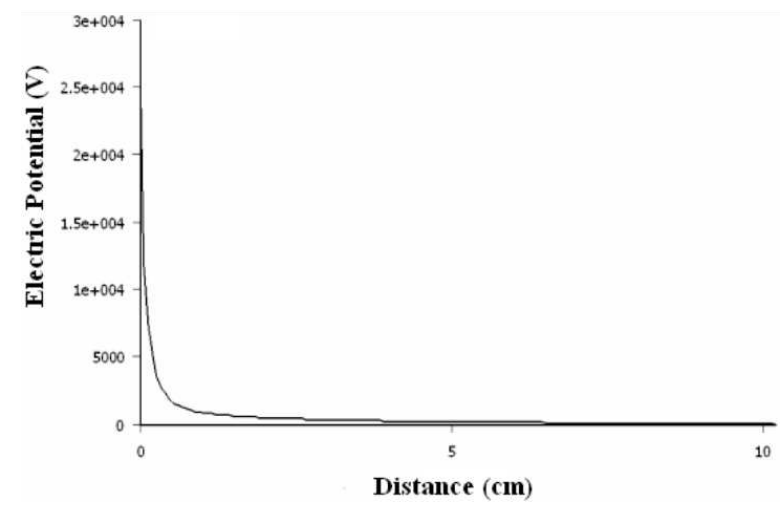

Fig. 4. Plot of electric potential along the surface of the solid cable insulator with different relative permittivities.

\section{Conclusions}

In this study, the relationship between electric field distribution and duration of use of insulators were investigated. We have conducted a laboratory experiment. 
In this experiment, polymeric insulators are exposed to different electric field, and high voltage levels.

As the results of the simulation with FEM modeling, flow point close to the earth potential as well as the flow point of the wet surface were determined to have high potential in the region between the ground electrode and high voltage electrode. Figure 3 shows simulated solid insulator, electric potential and electric field lines for polymer, which has relative permittivity value of insulation of test samples cables. Figure 4 shows that increasing relative permittivity, results an increase in the electric potential values on the cable insulator surface. Electric field strength was found to be higher than the electric field strength in the flow test.

\section{Acknowledgments}

This work was supported by the Research Fund of the University of Istanbul. Project number YADOP 20977.

\section{References}

[1] G. Karady, D. Srinivasan, IEEE Trans. Power Del. 16, 286 (2001).

[2] G. Karady, E. Al-Ammar, B. Shi, M.W. Tuominen, IEEE Trans. Power Del. 21, 450 (2006).
[3] G. Karady, G. Besztercey, M.W. Tuominen, IEEE Trans. Power Del. 14, 1438 (1999).

[4] US Patent 6519396, Aerial cable containing optical transmission elements and process for the manufacture of an aerial cable, US Patent Issued on February $11,(2003)$.

[5] E. Eroğlu, İ. Güney, I. Güneş, Acta Phys. Pol. A 121, 36 (2012).

[6] S. Kucuksari, İ. Gunes, G. Karady, in: 2009 IEEE Bucharest PowerTech, Bucharest 2009, p. 2337.

[7] C.P. Uzunoğlu, İ. Güneş, M. Uğur, Turkish J. Electric Eng. Computer Sci. 19, 109 (2011).

[8] İ. Güneş, Y. Özçelep, Istanbul Univ. J. Electric Electron. Eng (IU-JEEE) 8, 593 (2008).

[9] A. Ersoy Yilmaz, A. Kuntman, Int. Rev. Electric Eng. 6, 1046 (2011).

[10] F. Kaidanov, R. Munteanu, G. Sheinfain, IEEE Elect. Insul. Mag. 16, 16 (2000). 